\title{
Zeytinin (Olea europaea L.cv. Memecik) Sürtünme Katsayılarının Belirlenmesi
}

\author{
Ahmet ÇOLAK'
}

Kàmil SAÇILIK'

Geliş Tarihi : 23,06.2001

\begin{abstract}
Özèt : Bu çalışmada, Izmir yöresinde yetiştirilen Memecik zeytinin, çeşitli sürtunme yüzeyleri üzerindeki sürtünme katsayıları belirlenmiştir. Sürtünme katsayısı değerlerini belirlemek amacryla bir ölçme düzeni geliştirilmiştir. Ölçme düzeni, zeytinlerin içine konulduğu kutu, sürtünme yưzeyi ve kuvvet algılama düzeninden oluşmuştur. Sürtünme yüzeyi olarak lastik, kontrplak, galvanize sac ve krom çelik sac kullanılmıştır. Denemelerde normal kuvvet, 23.1, 28.1 ve $33.1 \mathrm{~N}$ olarak seçilmiş ve sistemde oluşan sürtünme kuvvetleri sürekli olarak veri ișleme sistemine kaydedilmiștir. Deneme sonuçlarına göre statik ve dinamik sürtünme katsayısı üzerine normal kuvvetin etkisi önemsiz, sủrtúnme yüzeyinin etkisi ise önemli bulunmuștur $(p<0.01)$. Normal kuvvetin artmasıyla statik ve dinamik katsayısında biraz azalma gózlenmiștir. Sürtünme katsayısının en yüksek deǧerleri lastik yūzeyde, en dụşük değerleñ ise krom çelik sacda elde edilmiştir.
\end{abstract}

Anahtar Kelimeler : zeytin, sürtünme yüzeyi, normal kuvvet, statik sürtünme, dinamik sûrtũnme

\section{Determination of the Coefficients of Friction of Olive (Olea europaea L.cv. Memecik)}

\begin{abstract}
In this study, the coefficients of friction of olive which were harvested in the region of Izmir were determined on various structural surfaces. A measurement system was developed to determine the coefficients of friction of olive. Measurement system consists of bottomless box that is filled with olives, test surface and data acquisition system. Rubber, plywood, galvanized steel and chrome stain steel were used as structural surface in the experiments. The experiments were executed at 23.1, 28.1 and $33.1 \mathrm{~N}$ normal force and friction force versus displacement was continuously recorded on files. The analysis of variance showed that test surface on the static and dynamic coefficient of friction is significant $(p<0.01)$. Normal force hasn't a significant effect on the static and dynamic coefficient of friction. However, the static and dynamic coefficient of friction has tendency to decrease with increases in normal force. Among the structural surfaces, rubber has the highest value of the static and dynamic coefficient of friction and chrome stain steel has the lowest one.
\end{abstract}

Key Words : olive, structural surface, normal force, static coefficient of friction, dynamic coefficient of friction

\section{Giriş}

Tarımsal ürünlerin fiziko-mekanik özelliklerinin bilinmesi, tarım makinalarının tasarım parametrelerine veri olması bakımindan oldukça önemlidir. Sürtünme, biyolojik materyallerin önemli fiziko-mekanik özellikleri arasındadır. Sürtünme değerlerinin bilinmesi, tarımsal ürünlerin iletiminde ve depolama özelliklerinin belirlenmesinde önemli rol oynamaktadı ( Puchalski ve Brusewitz 1996). Surtünme; silo ve benzeri depolama yapılarının yanal yüzeylerindeki düşey yüklerin belirlenmesinde, özellikle yôksek verdilerdeki pnömatik iletimde materyal ile yanal yüzeyler arasında ve yǐne tarımsal orünlerin presleme ve kesme işlemlerinde önèmini korumaktadır (Ögüt ve Çarman 1991). Ayrıca, sürtünme katsayısının farklı yüzeyler üzerinde çeşitli tarımsal ürünler için belirlenmesi, gộ kaynağının seçiminde ve buna bağlı olarak gerçek boyutların hesaplanmasinda etkili olmaktadır (Öztürk ve ark. 1995).

Tarimsal ürünlerin statik ve dinamik sürtũnme katsayıları uzerine yapılmı birçok araştıma bulunmaktadır. Bu çalışmalarda çeșitli tarımsal ürünlerin yüzey üzerine yaptığı basınç, kayma hızı, urân nemi, yüzey ozellikleri ve çevre koşullari gibi faktörlerin sürtunme katsayıları üzerine etkileri araştırilmıştır. Yapılan araştırmaların çoğu ise taneli biyolojik malzemeler için yapılmıştır. Bununla birlikte iri materyallerle daha az çalıșma yapilmıştır. Schaper ve Yaeger (1992) çalışmalarında, 9 farklı yüzeyde patatesin en buyük statik ve dinamik sürtünme katsayılarını belirlemişlerdir. Araştirma sonuçlarina göre patates çeşidinin sürtünme katsayıları azerine etkisinin onemsiz olduğunu; statik sürtünme katsayısının $0.34-0.73$, dinamik sürtünme katsayısının ise $0.34-0.66$ arasında değiştiğini araştırmalarında ifade etmişlerdir. Ozturk ve ark (1995), yığın haldeki şekerpancari ve havucun 5 kayma hızında sac, kontrplak, kaucuk ve elevatör yüzeyler kullanılarak statik ve dinamik sürtünme katsayılarını belirlemişlerdir. Gupta ve Das (1998), ayçiceğinin 5 farklı nem içeriğinde 6 değişik yüzey kullanarak statik ve dinamik sürtünme katsayılarını belirlemişlerdir. Deneme sonuçlarına göre en yüksek sürtünme katsayılarını lastik yüzeyde elde etmişlerdir. Statik sürtünme katsayısının paslanmaz çelik

\footnotetext{
'Ankara Üniv. Ziraat Fak. Tanm Makinaları Bölümü-Arikara
} 
için 0.351-0.472, lastik yüzey için ise $0.5140,651$ aralığinda olduğunu, dinamik sürtünme katsayisinin ise paslanmaz çelik için 0.304-0.441, lastik youzey içinde 0.447-0,593 olduğunu bulmuşlardir. Puchalski $v_{\theta}$ Brusewitz (1996), iki kavun çeşidinin statik ve dinamik sürtünme katsayılanm, 3 kayma hizı, 3 normal kuwat ve 6 değişik yozey kullanarak belirlemişlerdir Araştirma sonuiçarina gôre kayma hizi, hasat zamani ve yüzey parametrelerinin her iki sorturime katsayıs! ozerine etkisini onnemil bulmuş̧lardir. Kayma hizinin dinamik süntunme katsayını etkilemediğini araștırmalarında ifade etmişlerdir. Ayrica normal kuvvetin sürünme katsayilarini etkilemediğini, en youksek sartünme katsayilarinın lastik youzeyde elde edildiğini araștirmalarinda belirtmişlerdir. Beyhan ve ark (1994), araştimalarında yerli findik, tombul, palaz, kuș findigi ve sivri findik çeșitlerine ait tane ve zuruflu findiklarin statik ve dinamik surtunime Katsayilarini belirlemişlerdir. Tane ve zuruflu findikłar için 3 larklı nem dọzeyi; tane fındık için 10, zuruflu fındik için ise 11 sütünme yuzeyi kullanmişlardir. Statik ve dinamik surtunme katsayilari üzerine, nem ve yuzey özelliklerinin elkisini ónemli bulmuşlardir. Ayfica, sürtanme katsayisının en yukssek değerlerini lastik yuzeyde, en dūsäk değerlerini ise kontrplakta elde etmislerdir.

Yapilan kaynak araștimmasında zeytine ilișkin surtünme katsayısı verilerine rastlanamamıştir. Bu çalișmada, sofralik Memecik zeytinin (Olea europaea L cy. Memecik) degissik surtumme yuzeyleri uzerindeki statik ve dinamik sürtumme katsayılarınin, geliştirilen ôlçme düzeninde belirlenmesi amaçlanmıştır. Böylelikle veri tabanlannda yer alabilecek verilere ulaşilmaya çalışilmıştır.

\section{Materyal vé Yöntem}

Bu çalısmada, araştıma materyaii olarak sofralık uretimi yapilan Memecik zeytini (Olea europaea L. cV. Memecik) kullanilmiştir. Zeytinler, Izmir Zeytincilik Araștırma Enstitusạ bahçelerinden Aralik 2000 doneminde elle toplanmiş ve hasattan denemeye kadar ôlan saire içerisinde, $+4{ }^{\circ} \mathrm{C}$ de soğuk hava deposunda bekletilmiştir. Denemelerden önce zeytinler normal sıcaklığa ulaşmasi içio 24 saat oda sıcaklığında bırakılmıştır. Araștırmada kullanilan zeytinlere ait bazi fiziko-mekanik ozellikler Çizelge T'de verilmiștir.

Zeytinin sürtünme kátsayilarini belirlemek için Şekil 1 ' de görülen ölçme duzeni kullanıilmıştir. Ölçme düzeni, zeytinin konulduğu sac kutu, malzemesi deḡiştirilebilen surtanme yüzeyi ve kuvvet algilama sisteminden olușmaktadir Sac kutu, $250 \times 250 \times 90 \mathrm{~mm}$ olçolexrinde olup değișik surtünme yuzeyleri uzerinde, $1.67 \mathrm{~cm} / \mathrm{s}$ hizla hareket ettirilmiștir. Zeytinlerin sürtünme yüzeyi üzerinde rahat hareket etmesi ve kutu kenarinin sortonme yozeyine temas etmemesi için $10 \mathrm{~mm}$ boşluk birakilmiştır. Kutu içerisine her ölçômde aynı miktarda ürün doldurulmus ve denemelerde normal kuwet olárak 29.1, 28.1 ve 331 N'luk kuvvetler seçilmiş̧ir.

Surtunme yuzeyi olarak, lastik, kontrplak, galvanize sae ve Krom çelik sac kullanilmiştir. Değișik youzeyler için sürtünme uzakliḡi, $1000 \mathrm{~mm}$ alarak beliflenmiş ve her denemeden ônce sürtonme yözeyi temiz bir bez ile samizlenmiştir.
Çizelge 1. Ele alinan zeytinlerin bazı fiziko-mekanik özelliklefi

\begin{tabular}{lc}
\hline Ozellik & Değer \\
\hline Geomelrik ortalama çap $(\mathrm{mm})$ & 17.52 \\
Küresellik $(\%)$ & 79.17 \\
Hacim ağirlı̆̆l $\left(\mathrm{kg} / \mathrm{m}^{3}\right)$ & 581.76 \\
Nem $(\%)$ & 89,33 \\
Elastikiyef modola $\left(\mathrm{N} / \mathrm{mm}^{2}\right)$ & 3.45 \\
Renk koordinatı $(x ; y)$ & $(0.3189 ; 0,3244)$ \\
\hline
\end{tabular}

Yüzey üzerinde oluşan surtunme kuvveti, kuvvet algilama sistemi yardimiyla belirlenmiştir. Kuvvet algilama duzani, ölçme alanı $1000 \mathrm{kp}$ olan indoktif esaslı çeki bası dinamometresi, analog VoKseltici, modeli PCL-818 HG olan data ölçümleme kartı ve bu verileri işleyen IBM uyumiu PC den oluşmuştur. sürtanme yazzeyi azerinde oluşan kuvvetleri elektriksel boyokloklere dönoștoren çeki basi dinamometresi; verileri kesintișiz olarak bir ara kablosu aracilıgiyla analog yokselticiye oradan da data ölçumleme kartina iletmiştir. PCL-818 HG data álçumleme karti ise analog verileri sayisal verilere donusturerek bilgisayara aktarmiștir. Data öcçumleme karti, $\% 0.001$ ólçôm hassasiyetine sahip olup 0-10 V aralığındaki gerilimleri algılayabilmektedir. Data olęümleme kartından gelen sayisal sinyaller ise Genie 3.0 veri işleme programinda işlenerek sürtonme kuweti değerine donuşưüümùs ve bu veriler amaca uygun sekilde dosyalanmiştır. Denemeler suresince veri işleme programi, saniyede 50 veri kaydedecek şekilde ayarlanmıştır. Elde edilen sürünme deg̃erlerinin yer değiștirmeye bağli değișimi Şekil 2 'de verilmiștir. Statik surtünme kuweti olarak, kaydedilen verilerin en büyük degeri, dinamik sürtunme kuweti için ise en buyük. değerden sonra okunan değerlerin ortalamasi alinmiştir.

Her yüzey için denemeler 3 tekerrûtlu yapilmıs ve zedelenme göz ônüne alınarak her denemede yeni zeytin örnekleri kullanimiştir. Değerler alinmadan once her bir surtunme yüzeyi üzerinde deneme materyali hareket ettirilerek yözeyin uygun duruma getirilmesi sağlanmiştir Hesaplanan dinamik ve statik sörtönme katsayllannın yozey ozellikleri ile olan ilişkisini araștırmak için istatistiksel analizler yapilmiş ve sonuçlar irdelenmiștir.

\section{Bügülar ve Tartışma}

Denemeler sonucunda, zeytinler için elde edilen statik ve dinamlik süfunme katsayllan çizelge 2 ve a'te verilmiștic. Statik va dinamik sürtünme katsayısı değerlerine uygulanan varyans analizi sonuçlarina göre yüzeyin surtönme değerleri azerine etkisi önemli ( $p<0.01)$, normal kuvvet lle yozey x normal kuwet etkileșiminin sürtunme değerlerine etkisi ise önemsiz bulunmuştur.

Zeytin uzerine uygulanan $23,1,28,1$ ve 33,1 N'luk normal kuwvetlerin, dinamik ve statik sürtunme katsayisina etkisł önemsiz olmakla birlikte normal kuwvetin artmasıyla statik ve dinamik surturime katsayısi değerlerinde çok az bir azalma olmuştur (Çizelge 2). Normal kurvet arttikça sürtenme değerlerinde küçük bir azalma olduğunu Thompson ve ark. (1988), Zhang ve ark. (1994), Puchalski ve Brusewitz (1996) ve Kara ve ark. (1997)'da araștirmalarinda lfada etmişlerdir Bulunan sonuçarin literatâr sonuçari ile uyumiu olduğu gårülmüștán. 


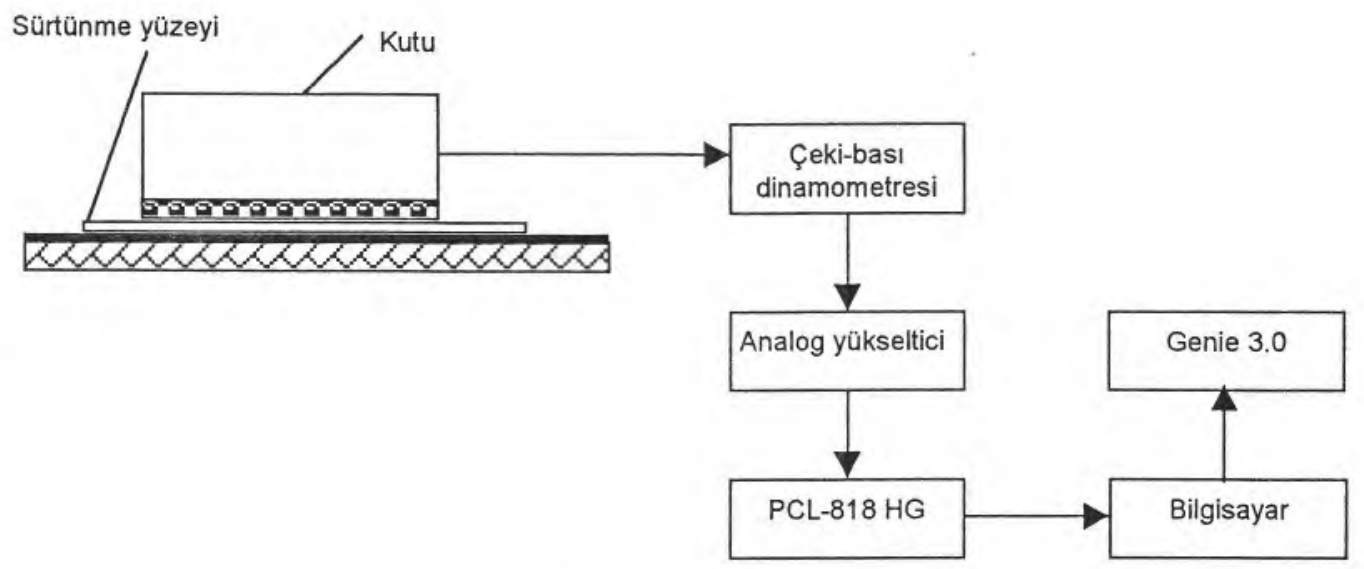

Şekil 1. Ölçme düzeninin şematik görünüşü

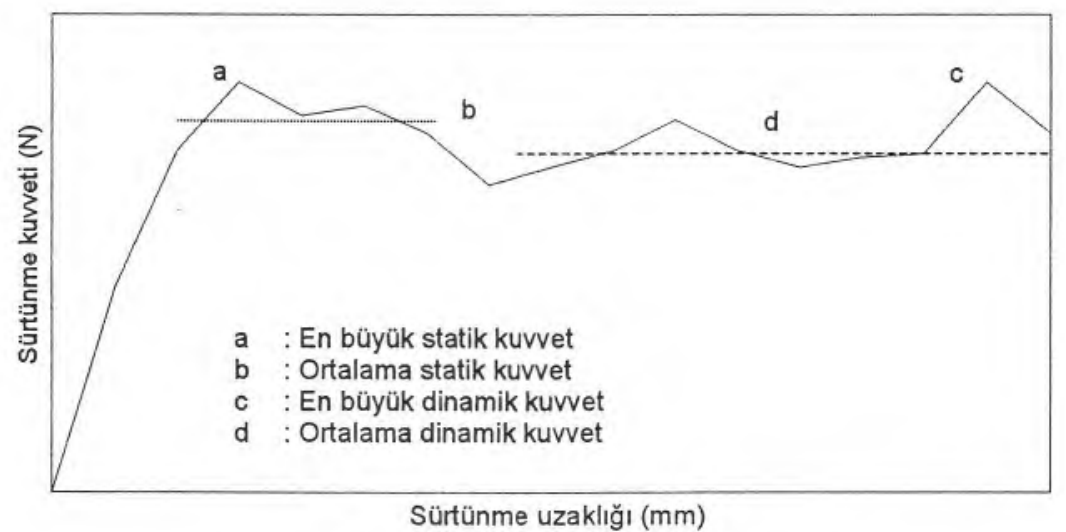

Şekil 2. Sürtünme uzaklığına bağlı sürtünme kuvvetleri

Çizelge 2. Zeytinlere ilişkin statik sürtünme katsayısı değerleri

\begin{tabular}{lcccc}
\hline & $23.1 \mathrm{~N}$ & $28.1 \mathrm{~N}$ & $33.1 \mathrm{~N}$ & Genel \\
\cline { 2 - 5 } Sürtünme yüzeyi & $\overline{\mathrm{x}} \pm \mathrm{S}_{\overline{\mathrm{x}}}$ & $\overline{\mathrm{x}} \pm \mathrm{S}_{\overline{\mathrm{x}}}$ & $\overline{\mathrm{x}} \pm \mathrm{S}_{\overline{\mathrm{x}}}$ & $\overline{\mathrm{x}} \pm \mathrm{S}_{\overline{\mathrm{x}}}$ \\
\hline Lastik & $0.63 \pm 0.020$ & $0.61 \pm 0.019$ & $0.60 \pm 0.027$ & $0.62 \pm 0.012 \mathrm{a}$ \\
Kontrplak & $0.50 \pm 0.018$ & $0.48 \pm 0.026$ & $0.49 \pm 0.017$ & $0.49 \pm 0.011 \mathrm{~b}$ \\
Galvanize sac & $0.43 \pm 0.024$ & $0.42 \pm 0.015$ & $0.42 \pm 0.019$ & $0.43 \pm 0.010 \mathrm{c}$ \\
Krom çelik sac & $0.42 \pm 0.023$ & $0.41 \pm 0.006$ & $0.40 \pm 0.009$ & $0.41 \pm 0.008 \mathrm{c}$ \\
\hline
\end{tabular}

$a, b, c:$ Aynı sütunda aynı harfle gösterilen ortalamalar arasında fark yoktur $(p<0.01)$.

Çizelge 3. Zeytinlere ilişkin dinamik sürtünme katsayısı değerleri

\begin{tabular}{lcccc}
\hline & $23.1 \mathrm{~N}$ & $28.1 \mathrm{~N}$ & $33.1 \mathrm{~N}$ & Genel \\
\cline { 2 - 5 } Sürtünme yüzeyi & $\overline{\mathrm{x}} \pm \mathrm{S}_{\overline{\mathrm{x}}}$ & $\overline{\mathrm{x}} \pm \mathrm{S}_{\overline{\mathrm{x}}}$ & $\overline{\mathrm{x}} \pm \mathrm{S}_{\overline{\mathrm{x}}}$ & $\overline{\mathrm{x}} \pm \mathrm{S}_{\overline{\mathrm{x}}}$ \\
\hline Lastik & $0.55 \pm 0.026$ & $0.54 \pm 0.041$ & $0.56 \pm 0.032$ & $0.55 \pm 0.017 \mathrm{a}$ \\
Kontrplak & $0.44 \pm 0.035$ & $0.43 \pm 0.015$ & $0.42 \pm 0.012$ & $0.43 \pm 0.012 \mathrm{~b}$ \\
Galvanize sac & $0.37 \pm 0.021$ & $0.36 \pm 0.006$ & $0.35 \pm 0.026$ & $0.36 \pm 0.010 \mathrm{c}$ \\
Krom çelik sac & $0.35 \pm 0.019$ & $0.34 \pm 0.006$ & $0.33 \pm 0.012$ & $0.34 \pm 0.007 \mathrm{c}$ \\
\hline
\end{tabular}

$a, b, c$ : Aynı sütunda aynı harfle gösterilen ortalamalar arasında fark yoktur $(p<0.01)$. 
Denemeye alınan lastik, kontrplak, galvanize sac ve krom çelik sac yüzeyin statik ve dinamik sürtünme katsayılarına etkisi önemli bulunmuştur. $(p<0.01)$ Yapılan çoklu karşılaştırma testinde lastik ve kontrplak yüzey arasındaki sürtünme katsayıları ortalamaları arasındaki farkın önemli $(p<0.01)$, galvanize sac ve krom çelik sac yũzey arasındaki farkın ise önemsiz olduğu görülmüştür (Çizelge 2 ve 3 ). Ortalama sürtünme değerleri dikkate alındığında ise en büyük sürtünme değerleri lastik yüzeyde görülmüștür. Lastik yüzeyi sırasıyla kontrplak, galvanize sac ve krom çelik sac izlemiştir.

Veri işleme sistemine kaydedilen veri dosyalarındaki statik ve dinamik sürtünme katsayılarının değişimi Şekil 3 ve 4 'de verilmiştir. Her veri dosyasında statik ve dinamik sürtünme kuvvetlerini temsil eden bölgeler belirlenmiștir. Bu bölgelere ilişkin verilerin ortanca değer etrafinda dağılımını ve verilerin $\% 75^{\prime}$ inin hangi değerler etrafında dağıldığı, bu grafiklerde kutu olarak verilmiştir. Ayrıca, bu değerlerin dışında kalanlar ise çubuk olarak kutulara eklenmiştir.

Lastik yüzeyin yumuşak olmasından dolayı sürtünme değerleri oldukça geniş bir aralıkta değişim göstermiştir. Bu aralık, statik sürtünme katsayısı için 0.51-0.74, dinamik sürtünme katsayısı için ise $0.40-0.75$ arasında olduğu gözlenmiştir. Verilerin ortanca etrafında dağılımı ise statik sürtünme katsayısı için $0,55-0.67$, dinamik sürtünme katsayısı için ise $0.48-0.62$ aralığında olmuştur. En düşük ve en yüksek statik sürtünme katsayısı; kontrplak yüzeyde $0.40-0.58$, galvanize sacda $0.38-0.52$ ve krom çelik sacda ise 0.36-0.49 arasında değişmiștir. En düşük ve en yüksek dinamik sürtünme katsayısı ise kontrplakta $0.32-0.57$, galvanize sacda $0.28-0.50$ ve krom çelik sacda ise 0.27 0.48 arasında değiştiği görülmüştür (Şekil 3 ve 4 ).

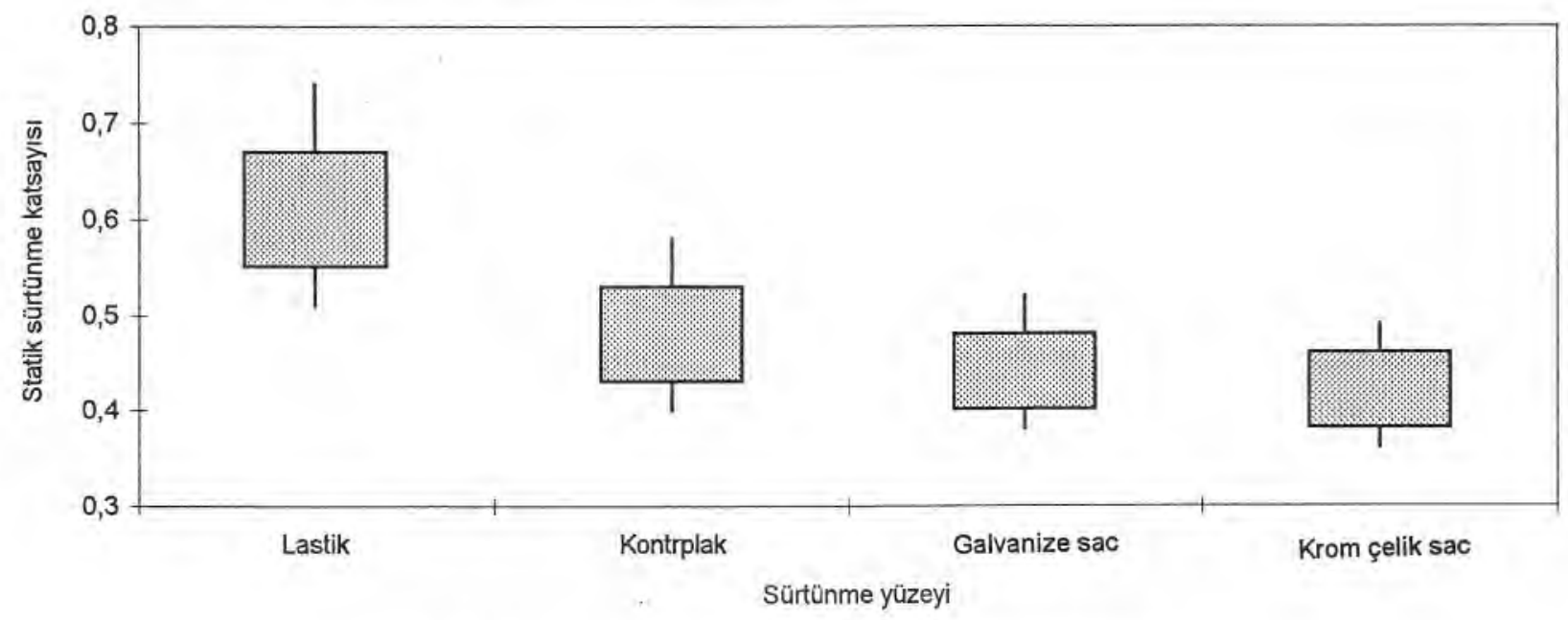

Şekil 3. Statik sürtünme katsayılarının çeşitli yüzeyler üzerindeki değişimi

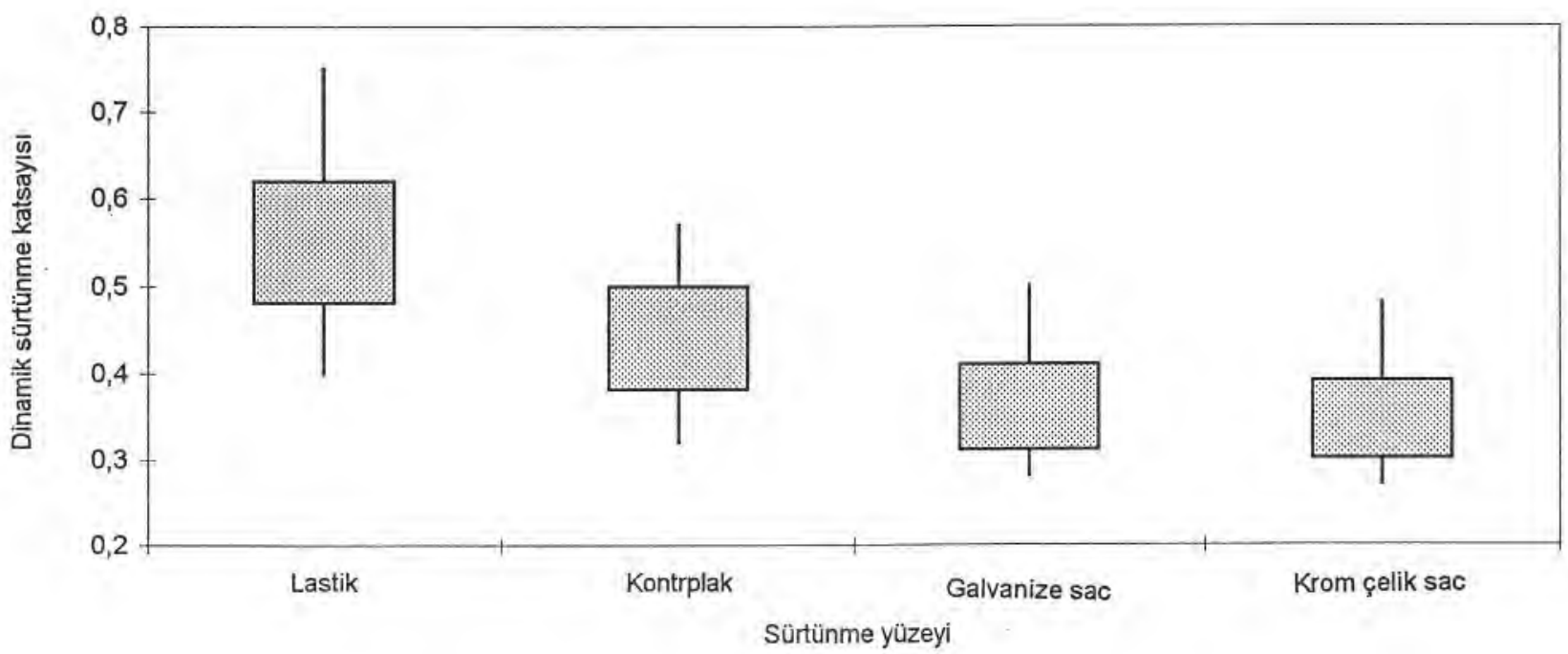

Şekil 4. Dinamik sürtünme katsayılarının çeşitli yüzeyler üzerindeki değişimi 
Galvanize sac ve krom çelik sac yüzeylerde elde edilen sürtünme değerleri diğer iki yüzeye göre dar bir aralıkta değişmiştir. Buna neden olarak yüzeylerin daha düzgün olması gösterilebilir. Ayrıca denemelerde en büyük dinamik sürtünme katsayısının, en büyök statik sürtünme katsayısına yaklaştığı görülmüştôr. Ancak ortalamalar dikkate alındığında ise dinamik sürtünme katsayısı; lastik yüzeyde 0.55 , kontrplakta 0.43 , galvanize sacda 0.36 ve krom çelik sac yüzeyde ise 0.34 bulunmuştur.

\section{Sonuç}

Zeytinin sürtünme katsayısının belirlenmesine ilişkin araştırma sonuçları aşağıdaki gibi özetlenebilir:

1. Denemelerde zeytin üzerine uygulanan $23.1,28.1$ ve 33.1 N'luk normal kuwetlerin statik ve dinamik sürtunme katsayılarına etkisi önemsiz bulunmuş ve normal kuvvet arttıkça her iki sürtünme katsayısı değerlerinde hafif bir azalma olduğu görülmüştûr.

2. Sürtünme yüzeyi, statik ve dinamik sürtünme katsayılarına etkisi önemli bulunmuştur $(p<0.01)$. Lastik ve kontrplak yüzey arasındaki sürtunme katsayıları ortalamaları arasındaki fark önemli iken galvanize sac ve krom çelik sac yüzey arasındaki farkın önemsiz olduğu görülmüştür En bayuâk statik ve dinamik sürtunme katsayısı lastik yüzeyde olmuștur. Bunu sırasıyla kontrplak, galvanize sac ve krom çelik sac izlemiştir.

3. Lastik yüzeyin yumuşak olmasından dolayı sürtünme değerleri oldukça geniş bir aralıkta değişim göstermiștir. Bu aralığın statik sürtünme katsayısı için $0.51-0.74$, dinamik sürtünme katsayısı için ise 0.40-0.75 arasında olduğu gözlenmiştir. Galvanize sac ve krom çelik sac yüzeylerde elde edilen sürtünme değerleri diğer iki yüzeye göre dar bir aralıkta değişmiştir.

4. Zeytinin ortalama statik sürtünme katsayısı; lastikte 0.62 , kontrplak yüzeyde 0.49 , galvanize sacda 0.43 ve krom çelik sacda ise 0.41 olarak bulunmuştur. Dinamik sürtünme katsayısı da lastik yüzeyde 0.55 , kontrplak yüzeyde 0.43 , galvanize sacda 0.36 ve krom çelik sacda 0.34 olarak bulunmuştur.

\section{Kaynaklar}

Beyhan, M. A., M. Nalbant ve A. Tekgüler, 1994. Tane ve zuruflu fındikların sürtünme katsayılarının belirlenmesi. Akdeniz Oniv. Tarımsal Mekanizasyon 15. Ulusal Kongresi Bildiri Kitabi, Antalya.

Gupta, R. K. and S. K. Das, 1998. Friction coefficent of sunflower seed and kernel on various structural surfaces. J. of Agric. Engineering Research, 71, 175-180.

Kara, M., N. Turgut, Y. Erkmen ve I. E. Güler, 1997. Bazı daneli urünlerin sürtünme katsayılarının belirlenmesi. Gaziosmanpaşa Üniv. Tanmsal Mekanizasyon 17. Ulusal Kongresi Bildiri Kitabi, Tokat.

Öğüt, H. ve K. Çarman, 1991. Bazı küçük daneli örünlerin sürtünme katsayılarının değişik yüzeyler için belirlenmesi. Selçuk Üniv. Tarımsal Mekanizasyon 13. Ulusal Kongresi Bildiri Kitabi, Konya.

Öztürk, R., A. Çolak ve Y, Sabahoğlu, 1995. Bazı yumru bitkilerin sürtünme katsayılarının belirlenmesi. Uludağ Üniv. Tarımsal Mekanizasyon 16. Ulusal Kongresi Bildiri Kitabı, Bursa.

Puchalski, C. and G. H. Brusewitz, 1996. Coefficent of friction of watermelon. Trancaction of the ASAE, 39 (2) 589-594.

Schaper, L. A and E. C. Yaeger, 1992. Coefficients of friction of irish potatoes. Transactions of the ASAE, 35 (5) 1647-1651.

Thompson, S. A., R. A. Bucklin, C. D. Batich and I. J. Ross, 1988. Variation in the apparent coefficient of friction of wheat on galvanized steel. Transactions of the ASAE, 31 (5) 15181524.

Zhang, Q., M. G. Britton and R. J. Kieper, 1994. Interactions between wheat and a corrugated steel surface. Transactions of the ASAE, 37 (3), 951-956. 